\title{
Scenario-Based Exposure Risk Assessment of Molinate in a Paddy Plot ; (2) Exposure Risk Assessment
}

\author{
시나리오별 논에서의 molinate 노출위험도 분석: (2) 노출위험도 평가 \\ Park, Ki-Jung ${ }^{*}$ Chung, Sang-Ok ${ }^{* *,+}$ \\ 박기중* 정상옥 ${ }^{* *+}$
}

\begin{abstract}
Exposure risk assessment of pesticide molinate using the RICEWQ model in a rice paddy plot was performed to observe the effects of various water and pesticide management scenarios. Several scenarios were developed to represent the specific water and pesticide management practices of rice cultivation in Korea. The results of the scenario analysis using the RICEWQ model simulation from the previous studies were analysed. The molinate risk for aquatic organisms is evaluated by the ratio of the predicted environmental concentration(PEC) and the predicted no-effect concentration(PNEC). The results showed that the no-effect periods for aquatic organisms for the deep, shallow and very shallow irrigation conditions were 33.3, 28.9 and 25.6 DATs for the lable rate application and 36.4, 33.7 and 30.8 DATs for the double lable rate application, respectively. The higher application rate showed greater exposure risk to the aquatic organisms. Based on this study, the withholding period of molinate practiced in Korea, that is 3 to 4 DATs, must be much longer. The results of this study can be used for the non-point source pollution control and environmental policy making regarding pesticides.
\end{abstract}

Keywords : exposure risk assessment, pesticide, molinate, paddy, RICEWQ, withholding period.

\section{Introduction}

Pesticides can be credited with providing sufficient low-cost supplies of food and saving labour. The perfect pesticide would be one which

\section{* $\quad$ Rural Research Institute}

** Kyungpook National University, Agricultural Engineering Department

$+\quad$ Corresponding author. Tel.: 82-53-950-5734

Fax: 82-53-950-6752

E-mail address: sochung@knu.ac.kr

2007년 8월 13일 투고

2008년 5월 16일 심사완료

2008년 6월 2일 게재확정 reaches the targets without adversely affecting any ecosystem. Due to frequent detection of pesticides and their products in the aquatic ecosystem, much attention has been paid to the non-point source(NPS) pollution by pesticides.

Following the release into the environment, pesticides can be disseminated in numerous ways, such as adsorption, transport and degradation, until they reach the target or non-target organisms. These mechanisms can give both positive and negative influences on effectiveness of pesticides or their impact on the environ- 
ment. Since the use of pesticides in agriculture inevitably threatens non-target organisms, undesirable side-effects may occur in some species, communities or on ecosystems as a whole.

Due to today's concern for conservation of aquatic ecosystem, there are increasing demands for preventing pesticides and other pollutants from entering water resources. Agriculture has been censured considerably for the presence of pesticides in adjacent aquatic ecosystem(Spencer et al., 1985). Deuel et al.(1979) found that the water quality of surface impoundments and estuaries could be adversely affected by pesticide loading via irrigation return flows.

Molinate is a selective, thiocarbamate herbicide used almost exclusively in rice production for control of weeds. Approximately $800 \mathrm{M} / \mathrm{T}$ of molinate active ingredient(a.i.) were used in Korea in 2004(KCPA, 2005a). In Korea, it was reported that molinate treated in rice paddies was a contributing factor in the phytotoxic symptom, and shrivelled leaves of the chilli pepper(Park, 2003). In addition, the Ministry of Environment classified molinate as endocrine disrupting chemicals(EDCs)(MOE, 2003). EDCs can alter hormone regulation, which controls the reproductive systems of aquatic and terrestrial organisms.

The objectives of this study are to assess the molinate exposure risk for adjacent aquatic organisms under several water and pesticide management scenarios and to propose an appropriate withholding period of discharge water from the paddy plot for ecosystem conservation.

\section{Materials and Methods}

\section{Scenario simulation}

In previous studies, Park (2007), Chung et al. (2008a,b) calibrated RICEWQ model with field data from Daegu and used to predict molinate concentrations for scenario analysis in rice paddies treated with molinate. Scenario analysis was performed to understand the potential effect of the different water depths and pesticide management practices on the predicted molinate concentrations. The water and pesticide management scenarios (Table 1) were selected based on the cultural practices adopted by the farmers in general as previously explained in detail (Chung et al., 2008a). Manual application with $100 \%$ application efficiency was adopted in the simulation. The scenarios were run for the growing season from 4 June to 2 September for ten years 1997-2006. Detail results of the scenario simulation were presented in Chung et al. (2008b).

Table 1 Water and pesticide management scenarios used in this study.

\begin{tabular}{|c|c|c|c|}
\hline \multirow{2}{*}{ Scenarios } & \multicolumn{2}{|c|}{ Water management } & \multirow{2}{*}{$\begin{array}{c}\text { Molinate } \\
\text { application rate }\end{array}$} \\
\hline & ponding depth & value $(\mathrm{cm})$ & \\
\hline $\mathrm{A}$ & deep & $6-10$ & \multirow{3}{*}{$\begin{array}{l}\text { label rate } \\
(1.5 \mathrm{~kg} / \mathrm{ha})\end{array}$} \\
\hline B & shallow & $4-8$ & \\
\hline $\mathrm{C}$ & very shallow & $2-6$ & \\
\hline $\mathrm{D}$ & deep & $6-10$ & \multirow{3}{*}{$\begin{array}{c}\text { double label rate } \\
\quad(3.0 \mathrm{~kg} / \mathrm{ha})\end{array}$} \\
\hline $\mathrm{E}$ & shallow & $4-8$ & \\
\hline $\mathrm{F}$ & very shallow & $2-6$ & \\
\hline
\end{tabular}

\section{Risk assessment}

The U.S. EPA's Framework for Ecological Risk Assessment(1992) defines an ecological risk assessment as a process that evaluates the likelihood that adverse ecological effects on populations may occur or are occurring as a result of exposure to one or more stressors. A stressor is defined as any physical, chemical, or biological entity that can induce an adverse ecological response. The primary functions of an ecological risk assessment are to(TNRCC, 
1996):

- document whether actual or potential ecological risk exists at a site,

- screen the contaminants present to identify those that might pose an ecological risk, thereby focusing further efforts, and

- if necessary, generate data to be used in evaluating cleanup options.

In order to assess the ecological impacts of released pesticides, information is usually required concerning the likelihood of exposure of aquatic organisms to the constituents in pesticides. The predicted environmental concentration(PEC) and the predicted no-effect concentration(PNEC) are used to assess the ecological impacts. The risk assessment scheme regarding pesticides for adjacent water environments in Korea is summarized in Fig. 1.

The PEC is the predicted concentration of a pesticide within an environmental compartment based on estimates of the quantities released, discharge patterns, and the inherent disposition of the pesticide(fate and distribution); it also takes into account of the nature of the specific receiving ecosystems. The PNEC is the estimated no-observed-effect concentration for an aquatic species in the ecosystem based on extrapolated

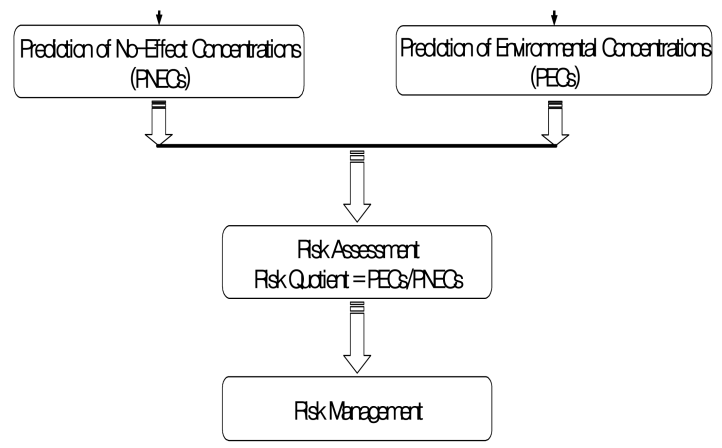

Fig. 1 The risk assessment scheme regarding pesticides for aquatic environment in Korea (Ryu, 2002) experimental exposure/response data(Stephenson et al., 2006).

The pesticide exposure risk for aquatic organisms is evaluated by the risk quotient ( $R Q$ ) ratio as defined by $\mathrm{PEC} / \mathrm{PNEC}$. RQ shows relative risk posed by a given use of pesticides (van der Werf, 1996). The PNEC can be derived from the toxicity endpoint, i.e., median lethal concentration, LC50 divided by the assessment factor(AF). The LC50 is a statistically derived concentration in an environmental medium expected to produce a certain effect in $50 \%$ of the test organisms in a given population under defined conditions(Stephenson et al., 2006). Usually, AF values of 10 for algae and aquatic plants and 100 for invertebrates and fishes are used for assessing the potential risk to aquatic organisms (The Council of the European Communities. 1991). The PEC can be observed through field experiments or estimated by models. An inherent feature of the PEC of the released pesticides is that load cannot be monitored with reasonable accuracy or cost. Furthermore, PEC is influenced strongly by the chemical and physical properties of the pesticide as well as site characteristics such as soil, geology, vegetation, climate and weather, and the handling practices of the pesticide user. As a result, researchers and policy analysts increasingly rely on mathematical models to estimate PEC.

The LC50 for molinate used in standard risk assessment procedure for pesticide registration purposes, were obtained from databases(PAN, 2006; US EPA, 2003) and is presented in Table 2. The reported toxicity to aquatic organisms varies greatly. For example, LC50 values are 0.30mg/L for Daphnia magna and $0.60 \mathrm{mg} / \mathrm{L}$ for Stoneflies. For freshwater fishes, it is reported $0.32 \mathrm{mg} / \mathrm{L}$ for bluegill sunfish and $30.00 \mathrm{mg} / \mathrm{L}$ for 
Table 2 Toxicological endpoints(LC50) and PNEC for molinate in aquatic organisms (The Council of the European Communities. 1991)

\begin{tabular}{c|c|c|c|c|c}
\hline \multicolumn{2}{|c|}{ Species } & LC50(mg/L) & Assessment Factor & PNEC(mg/L) & Risk* Class \\
\hline \hline \multirow{2}{*}{ Aquatic invertebrates } & Daphnia magna & 0.30 & 100 & 0.0030 & no \\
\cline { 2 - 6 } & Stoneflies & 0.60 & 100 & 0.0060 & low \\
\hline \multirow{2}{*}{ Algae } & Selenastrum capricornutum & 0.22 & 10 & 0.0220 & moderate \\
\hline \multirow{2}{*}{ Freshwater fishes } & Bluegill sunfish & 0.32 & 100 & 0.0032 & low \\
\cline { 2 - 6 } & Goldfish & 30.00 & 100 & 0.3000 & high \\
\hline Aquatic plants & Lemna gibba & 3.30 & 10 & 0.3300 & high \\
\hline
\end{tabular}

* classified in this study

goldfish. LC50 values for algae(Selenastrum capricornutum) and aquatic plants(Lemna gibba) are $0.22 \mathrm{mg} / \mathrm{L}$ and $3.3 \mathrm{mg} / \mathrm{L}$, respectively. This implies that levels above these values may lead to adverse effects on populations for each aquatic organism.

In this study, to assess the exposure risk to aquatic organisms, predicted molinate concentrations were grouped into four risk classes based on the professional judgment; no risk concentration range is lower than $0.003 \mathrm{mg} / \mathrm{L}$, the low is from $0.003 \mathrm{mg} / \mathrm{L}$ to $0.01 \mathrm{mg} / \mathrm{L}$, the moderate is from $0.01 \mathrm{mg} / \mathrm{L}$ to $0.1 \mathrm{mg} / \mathrm{L}$, and the high is higher than $0.1 \mathrm{mg} / \mathrm{L}$.

\section{Withholding period}

One of the most important elements in best management practices is to decide the withholding period in order to conserve the aquatic ecosystem through risk assessment. The current guidelines, set for pesticide residues in ponded water by the New South Wales Environmental Protection Authority in Australia, are $0.0125 \mathrm{mg} / \mathrm{L}$ as a notification level and $0.0250 \mathrm{mg} / \mathrm{L}$ as an action Level (NSW EPA, 2004), while the Japanese Environment Agency sets $0.050 \mathrm{mg} / \mathrm{L}$ (Hamilton et al., 2003).

In Korea, however, the withholding period of general pesticides in rice paddies is 3 to 7 days after treatments(DATs), and that of the molinate is 3 to 4 DATs(KCPA, 2005b). In California, molinate was responsible for major fish kills in the Sacramento River through the late 1980s, and contaminated the drinking water for the city of Sacramento with taste and smell unacceptable to residents. To reduce the amount of molinate and other rice pesticides discharged into the surface water, the California Department of Pesticide Regulation instituted controls on discharge flows from rice fields in 1983. Discharge water was held on molinate treated rice paddies for 28 days after application. With this restriction, molinate concentrations in Sacramento Valley rivers declined substantially from the previous levels, and fish kills were greatly reduced (Newhart, 2002; Kegley, 2003).

In this study, the withholding periods are re-suggested based on the risk assessment for aquatic organisms. The European Food Safety Authority(EFSA) reported that Daphnia magna was the most sensitive species of all the tested aquatic organisms(EFSA, 2006). Therefore, the withholding period for ponded water in rice paddies was reconfirmed and redefined as the safe detection period for Daphnia magna in this study. 


\section{Results and Discussion}

\section{Risk assessment on water management scenarios}

Table 3 shows the results of the risk exposure assessment for different water management scenarios (A, B, C) for molinate applied with the label rate in ponded water.

In the deep irrigation condition, for the high risk class, PNEC (the critical concentraion) was detected until 13.7 DATs. For the low risk class it was detected until 33.2 DATs. The very shallow ponding condition showed that it was able to prevent adverse ecological effects on populations earlier; high risk class persisted until 10.3 DATs, moderate class until 20.3 DATs, and low class until 25.5 DATs.

The no-effect periods for Daphnia magna for the deep, shallow and very shallow irrigation condition were at 33.3, 28.9 and 25.6 DATs, respectively. Therefore, it is recommended that the withholding period for these conditions should be longer than 26 to 33 DATs depending on the ponding depth to prevent the adverse ecological effects on populations.

Based on the water management scenario analysis, the very shallow irrigation method could ensure a sustainable water resource and also had the benefit of protecting aquatic ecosystems from pesticide exposure. However, very shallow irrigation must be carefully attended for the first 5 DATs, because the molinate concentration is very high during this period as shown in Fig. 2.

Table 3 Summary of the results of risk assessment for molinate treated with the label rate using the different water management methods

\begin{tabular}{c|c|c|c|c}
\hline \multirow{2}{*}{ Risk Class } & PNEC(mg/L) & \multicolumn{3}{|c}{ Detection Period(DATs) } \\
\cline { 3 - 5 } & $\begin{array}{c}\text { Scenario A } \\
\text { (Deep) }\end{array}$ & $\begin{array}{c}\text { Scenario B } \\
\text { (Shallow) }\end{array}$ & $\begin{array}{c}\text { Scenario C } \\
\text { (Very } \\
\text { shallow) }\end{array}$ \\
\hline \hline High & higher than 0.100 & 13.7 & 12.5 & 10.3 \\
\hline Moderate & 0.010 to 0.100 & 26.0 & 22.6 & 20.3 \\
\hline Low & 0.003 to 0.010 & 33.2 & 28.8 & 25.5 \\
\hline No Risk & lower than 0.003 & after 33.3 & after 28.9 & after 25.6 \\
\hline
\end{tabular}

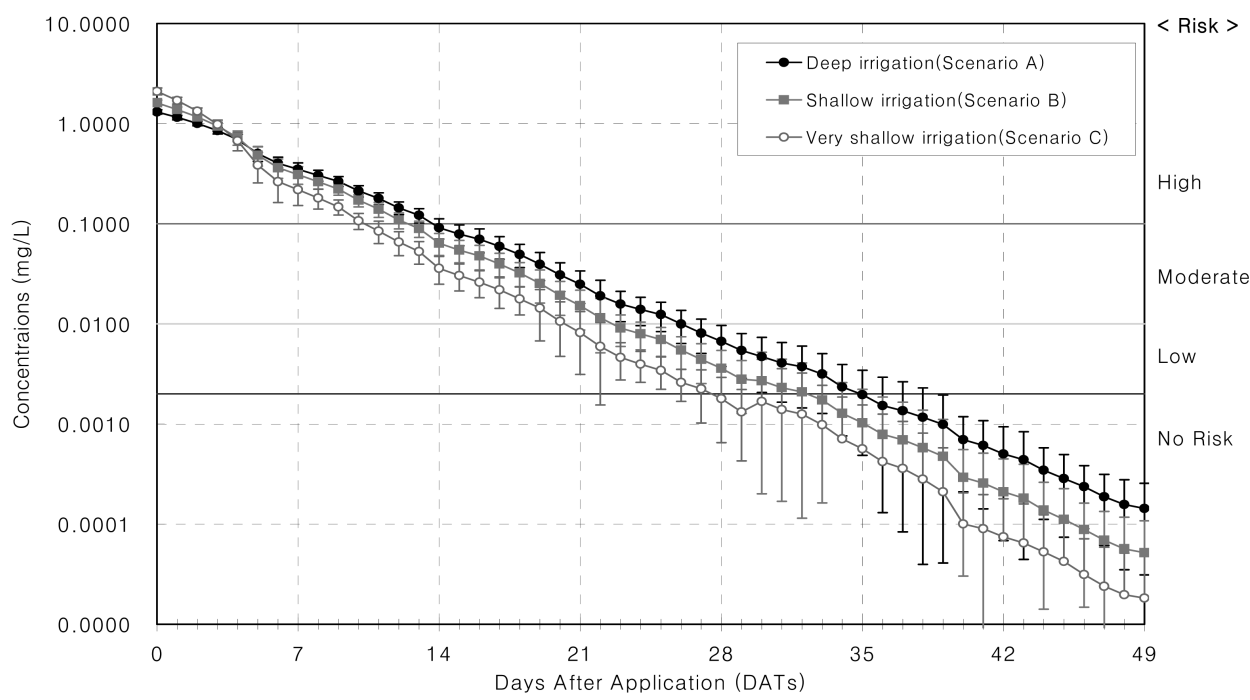

Fig. 2 Risks for molinate exposure for the different water management methods during 1997 to 2006 (vertical bars are standard deviations) 


\section{Risk assessment on pesticide treatment amount scenarios}

Table 4 shows the results of the risk exposure assessment for the double label rate molinate treatment on aquatic organisms(scenarios D, E, F). When comparing molinate risk for aquatic organisms, the deep irrigation condition showed longer detection period than the other conditions. In the deep irrigation condition, High risk class detected PNEC until 17.9 DATs and Low risk class detected critical concentration until 36.3 DATs. In contrast to the deep and shallow irrigation conditions, the very shallow irrigation condition was able to prevent the adverse ecological effects on populations earlier; the high class persisted until 13.2 DATs, the moderate class until 22.7 DATs, and the low class until 30.7 DATs. After 30.8 DATs, molinate risk was not observed under the shallow irrigation condition.

Based on these results, for a molinate treatment of double label rate in rice paddies with deep, shallow and very shallow conditions, the noeffect periods for Daphnia magna were at 36.4, 33.7 and 30.8 DATs, respectively. Therefore, it is recommended that the withholding period for these conditions should be longer than 31 to 36 DATs depending on the ponding depth.

Table 4 Summary of the results of risk assessment for molinate treated with the double label rate using the different water management methods

\begin{tabular}{c|c|c|c|c}
\hline \multirow{2}{*}{ Risk Class } & PNEC(mg/L) & \multicolumn{3}{|c}{ Detection Period(DATs) } \\
\cline { 3 - 5 } & & $\begin{array}{c}\text { Scenario D } \\
\text { (Deep) }\end{array}$ & $\begin{array}{c}\text { Scenario E } \\
\text { (Shallow) }\end{array}$ & $\begin{array}{c}\text { Scenario F } \\
\text { (Very } \\
\text { shallow) }\end{array}$ \\
\hline \hline High & higher than 0.100 & 17.9 & 15.7 & 13.2 \\
\hline Moderate & 0.010 to 0.100 & 29.6 & 26.5 & 22.7 \\
\hline Low & 0.003 to 0.010 & 36.3 & 33.6 & 30.7 \\
\hline No Risk & lower than 0.003 & after 36.4 & after 33.7 & after 30.8 \\
\hline
\end{tabular}

The label rate scenarios had shorter detection period than the double label rate scenarios as expected. These results show that the application rate not higher than the specified label value will provide more effective and environmentally sound pest management.

\section{Conclusions}

In this study, the results of RICEWQ model simulations under various scenarios were used to assess the molinate risk to aquatic organisms. Based on the exposure risk assessment, the withholding periods for discharge water from rice paddies was re-suggested. Results obtained from this study are summarized as follows:

1. Based on the water management scenario analysis, the no-effect periods for aquatic organisms for the deep, shallow and very shallow irrigation conditions were 33.3, 28.9 and 25.6 DATs, respectively. Therefore, it is recommended that the withholding period for these conditions should be longer than these values.

2. Based on the pesticide treatment amount scenario analysis, for a molinate treatment of double label rate in rice paddies with deep, shallow and very shallow conditions, the recommended withholding periods were 36.4, 33.7 and 30.8 DATs, respectively.

3. In Korea, the withholding period in the case of molinate used in rice paddies has been about 3 to 4 DATs, as recommended by the pesticide label rate. But, for adjacent aquatic organism conservation, the withholding period must be much longer according to present study.

4. The label rate scenarios showed shorter detection period than the double label rate 
scenarios. These results show that using the application rate not higher than the specified label value will provide more effective and environmentally sound pest management.

The results of this study can serve to establish limits of pesticide concentrations in discharge water from rice paddies and provide with basic information for the best management practices for the ecosystem conservation. They may also serve to implement the risk reduction strategies, so that environmental receptors can be protected.

\section{References}

1. Chung, S.O., K.J. Park \& S.H. Son, 2008a, Calibration and Sensitivity analysis of the RICEWQ model, Journal of the Korean Society of Agricultural Engineers, 50(2), pp.3-10.

2. Chung, S.O., K.J. Park \& S.H. Son, 2008b, Scenario-Based Exposure Risk Assessment of Molinate in a Paddy Plot : (1) Analysis of simulation results, Journal of the Korean Society of Agricultural Engineers, 50(2), pp. 11-16.

3. Deuel, L.E., J.D. Price, F. Turner \& K.W. Brown, 1979, Persistence of Carbofuran and Its Metabolities, 3-keto and 3-hydroxy carbofuran, underflooded rice culture, Journal of Environmental Quality, 8(1), pp.23-26.

4. European Food Safety Authority(EFSA), 2006, Opinion of the Scientific Panel on Plant health, Plant Protection Products and Their Residues on a Request from the EFSA Related to the Aquatic Risk Assessment for Cyprodinil and the Use of a Mesocosm Study in Particular, The EFSA Journal, 329, pp.1-77.

5. Hamilton, D.J., Á. Ambrus, R.M. Dieterle,
A.S. Felsot, C.A. Harris, P.T. Holland, A. Katayama, N. Kurihara, J. Linders, J. Unswarth \& S.-S. Wong, 2003, Regulatory Limits for Pesticide Residues in Water, Pure and Applied Chemistry, 75(8), pp.1231155.

6. Kegley, S., 2003, Molinate on Rice, Pesticide Action Network North America, Accessed on April 11, 2008, http://www.panna.org/ resources/gpc/gpc_200312.13.3.03.dv.html.

7. Korea Crop Protection Association(KCPA), 2005a, Pesticide Year Book, 745p. (In Korean).

8. Korea Crop Protection Association(KCPA), 2005b, Instruction manual for pesticide application, 1015p. (In Korean).

9. Ministry of Environment (MOE), Republic of Korea, 2003, Endocrine Disrupting Chemicals (EDCs) Research Plane 2003, 35p.(in Korean)

10. Newhart, K.L., 2002, Rice Pesticide Use and Surface Water Monitoring 2002, Department of Pesticide Regulation, Report \#EH02-09, 36p.

11. NSW Environment Protection Authority, 2004, Environment Protection Licence No. 4651, NSW, Australia.

12. PAN Pesticide Database, Accessed on January 17, 2006, at http://www.pesticideinfo.org/ Index.html.

13. Park, B.J., 2003, Studies on the Fate of Herbicide, Molinate in Paddy Rice Ecosystem, Ph.D. Thesis, Dept. of Agricultural Chemistry, Chonnam National University, Gwangju, Korea. (in Korean).

14. Park, K.J., 2007, Scenario-based simulation for molinate concentrations in rice paddies using RICEWQ model, Ph.D. Thesis, Dept. of Agricultural Engineering, Kyungpook National University, Daegu, Korea.

15. Ryu, G.H., 2002, Present status and future perspectives of the pesticide safety manage- 
ment in Korea, Proceedings of the 27th Korean Public Health Association Conference, p.11.

16. Spencer, W.F., M.M. Cliath, J.W. Blair \& R.A. LeMert, 1985, Transport of Pesticides from Irrigated Fields in Surface Runoff and Tile Drain Waters, US Department of Agriculture, Agricultural Research Service, Report 31, Washington, DC, USA, 76p.

17. Stephenson, D.R., I.G. Ferris, P.T. Holland \& M. Nordberg, 2006, Glossary of Terms Relating to Pesticides(IUPAC Recommendations 2006), Pure and Applied Chemistry, 78(11), pp.2075-2154.

18. Texas Natural Resource Conservation Commission(TNRCC), 1996, Guidance for Conducting Ecological Risk Assessments Under the Texas Risk Reduction Program, Office of Waste Management, RG-263, Austin, Texas, USA.
19. The Council of the European Communities, 1991, Council Directive concerning the placing of plant protection products on the market (91/414/EEC), 194p.

20. U.S. EPA, 1992, Framework for Ecological Risk Assessment, Risk Assessment Forum, Washington DC, EPA/630/R-02/011.

21. U.S. EPA, 2003, Re-registration Eligibility Decision for Propanil, Office of Pesticide Programs, Special Review and Re-registration Decision.

22. van der Werf, H.M.G., 1996, Assessing the impact of pesticides on the environment, Agriculture, Ecosystems \& Environment, 60, pp.81-96. 